\title{
Proteomic Profile of Epithelioid Sarcoma
}

Kenta Mukaihara', ${ }^{1,2}$, Daisuke Kubota ${ }^{3}$, Akihiko Yoshida4, Naofumi Asano ${ }^{1}$, Yoshiyuki Suehara², Kazuo Kaneko ${ }^{2}$, Akira Kawai ${ }^{3}$ and Tadashi Kondo $^{1 *}$

${ }^{1}$ Division of Pharmacoproteomics, National Cancer Center Research Institute, Tokyo, Japan ${ }^{2}$ Department of Orthopedic Surgery, Juntendo University School of Medicine, Tokyo, Japan ${ }^{3}$ Division of Musculoskeletal Oncology, National Cancer Center Hospital, Tokyo, Japan

${ }^{4}$ Pathology and Clinical Laboratory Division, National Cancer Center Hospital, Tokyo, Japan

\begin{abstract}
Epithelioid sarcoma (ES) is a rare soft tissue sarcoma affecting young adults. It is a slow-growing tumor with a high rate of recurrence and metastasis to lymph nodes. Although deletion of the tumor suppressor gene, SMARCB1/ INI1, has been identified in ES, the molecular background factors are largely unknown. To clarify the molecular aberrations contributing to the malignant features of ES, we investigated the proteins present in ES tumor tissues. Two-dimensional difference gel electrophoresis of homogenized tissue samples revealed 3363 protein spots, of which 91 showed differences in intensity between tumor and adjacent non-tumor tissues in eight ES cases. Using mass spectrometry, we characterized 69 unique proteins corresponding to these protein spots. We found that the complex histology of ES was obstacle for the investigation of molecular backgrounds of ES. For instance, although the higher expression of CAPZB in tumor tissues was confirmed by Western blotting, the immunohistochemistry did not determine the specific localize CAPZB in tumor cells. Our study demonstrated the possible utility of proteomic study, and at the same time the difficult aspect of proteomics using homogenized tissue samples.
\end{abstract}

Keywords: Epithelioid sarcoma; Proteomics; 2D-DIGE

\section{Introduction}

Epithelioid sarcoma (ES) is a soft tissue sarcoma affecting young adults [1]. ES is classified into two subtypes according the pathological observations: a classic form that often arises in the classic extremities as a slow-growing nodule [2], and a proximal form that tend to arise in deep areas of the pelvis, perineum, and genital tract [3]. Although the proximal form may have a more aggressive clinical course than the classic forms [4], the clinical courses are diverse, even for identical subtypes. Previous reports have focused on clinical and pathological prognostic factors associated with ES [3,5-7]. Recently, deletion of the SMARCB1/ INI1 tumor-suppressor gene (INI1) was reported in proximal-type ES [8], and loss of its expression was observed in approximately $90 \%$ of classic and proximal ES cases [9]. The tumorigenic properties of INI1 genetic inactivation have been reported [10], and loss of INI1 protein expression in ES has been shown to be due to epigenetic mechanisms of gene silencing by specific miRNAs [11]. As well as molecular studies of INI1, a large-scale immunohistochemical study has revealed that loss of INI1 expression had no prognostic impact on ES [4]. These reports suggest that there may be a molecular basis for differences in the clinical and pathological features of ES, and that further investigations to identify these aberrations might have clinical relevance.

To investigate the molecular basis of the malignant features of ES, previous studies have employed global molecular analysis. In a global gene expression study to identify the invasive potential of ES, Weber et al. carried out differential display RT-PCR with arbitrary primers using ES cell lines differing in their invasive potential, and found that expression of apoferritin light chain, GRU-1A, cytochrome $c$ oxidase I, TI-227H, and ELISC-1 was associated with differences in invasiveness [12]. Using comparative genomic hybridization, Lushnikova et al. [13] examined DNA copy number changes in ES and reported recurrent gain at 11q13, and using immunohistochemistry confirmed overexpression of the cyclin D1 gene, located in 11q13. These studies suggested that a global molecular approach was effective, and that further investigations of a similar nature were warranted in ES. However, modern technology has not yet been applied for global molecular analysis of ES.
In the present study, to clarify the molecular background of ES, we adopted a proteomics approach using primary tumor tissues of ES. Proteomics can provide unique data that cannot be obtained using other global approaches. Using two-dimensional difference gel electrophoresis (2D-DIGE) and mass spectrometry [14], we identified proteins showing differential expression between tumor tissues and surrounding non-tumor tissues obtained from the ES patients.

\section{Materials and Methods}

\section{Patients and tumor samples}

This study included 8 patients with ES who were treated at the National Cancer Center Hospital between 1993 and 2013. Tumor and adjacent non-tumor tissues were obtained at the time of surgery, and stored in liquid nitrogen until use. Table 1 summarizes the patients' clinical and pathological information. This project was approved by the ethical review board of the National Cancer Center, and signed informed consent was obtained from all of the study patients.

\section{Protein expression profiling}

Proteins were extracted from frozen tissues as described previously [14]. In brief, tumor tissues were powdered with a Multi-beads shocker (Yasui Kikai, Osaka, Japan) in the presence of liquid nitrogen, and treated with urea lysis buffer (6 M urea, $2 \mathrm{M}$ thiourea, 3\% CHAPS, $1 \%$ Triton X-100). After centrifugation at $15,000 \mathrm{rpm}$ for $30 \mathrm{~min}$, the

*Corresponding author: Tadashi Kondo, MD, PhD, Division of Pharmacoproteomics, National Cancer Center Research Institute, 5-1-1 Tsukiji, Chuo-ku, Tokyo 104-0045, Japan, Tel: +81-3-3542-2511; Fax: +81-3-3547-5298; E-mail: takondo@ncc.go.jp

Received May 20, 2014; Accepted June 19, 2014; Published June 24, 2014

Citation: Mukaihara K, Kubota D, Yoshida A, Asano N, Suehara Y, et al. (2014) Proteomic Profile of Epithelioid Sarcoma. J Proteomics Bioinform 7: 158-165. doi:10.4172/0974-276X.1000316

Copyright: (c) 2014 Mukaihara K, et al. This is an open-access article distributed under the terms of the Creative Commons Attribution License, which permits unrestricted use, distribution, and reproduction in any medium, provided the original author and source are credited 


\begin{tabular}{|c|c|c|c|c|c|c|c|c|c|c|c|c|c|c|}
\hline $\begin{array}{c}\text { Case } \\
\text { no. }\end{array}$ & Age & Gender & Location & Subtype & $\begin{array}{c}\text { INI1 } \\
\text { expression }\end{array}$ & Grade $^{a}$ & $\begin{array}{c}\text { TNM } \\
\text { stage }^{b}\end{array}$ & Treatment & $\begin{array}{c}\text { Local } \\
\text { reccurence }\end{array}$ & $\begin{array}{c}\text { Lymph } \\
\text { node } \\
\text { metastasis }\end{array}$ & $\begin{array}{c}\text { Initial } \\
\text { metastatic } \\
\text { sites }\end{array}$ & $\begin{array}{c}\text { Disease-free } \\
\text { survival } \\
\text { (months) }\end{array}$ & $\begin{array}{c}\text { Overall } \\
\text { survival } \\
\text { (months) }\end{array}$ & Outcome \\
\hline ES_1 & 29 & $\mathrm{~F}$ & Perineum & lassic & egative & 2 & III & Curative surgery & Present & Absent & Lymph node & 12 & 143 & DOD \\
\hline ES_2 & 52 & M & Perineum & Proximal & Negative & 2 & IIA & Curative surgery & Present & Present & Lymph node & 9 & 168 & DOD \\
\hline ES_3 & 36 & M & Inguinal & Proximal & Negative & 3 & NA & Curative surgery & Present & Absent & Lung & 25 & 113 & DOD \\
\hline ES_4 & 64 & $\mathrm{~F}$ & Back & Proximal & Positive & 3 & III & Curative surgery & Present & Absent & Lung & 7 & 17 & DOD \\
\hline ES_5 & 32 & $M$ & Lower leg & Classic & Negative & 3 & III & Curative surgery & Absent & Absent & Lymph node & 19 & 35 & DOD \\
\hline ES_6 & 48 & $\mathrm{~F}$ & Axilla & Proximal & Negative & 3 & IV & Palliative treatment & Present & NA & Lung & NA & 4 & DOD \\
\hline ES_7 & 22 & $M$ & Foot & Classic & NA & 2 & IIA & Curative surgery & Absent & Absent & Bone & 10 & 18 & DOD \\
\hline ES_8 & 41 & M & Perineum & Classic & Negative & 2 & III & Curative surgery & Present & Present & Lymph node & 10 & 19 & DOD \\
\hline
\end{tabular}

NA: Data not available DOD: Dead of disease

aModified FNCLCC (French Federation of Cancer Centers) system (Coindre et al. Cancer. 1986, 58: 306-309).

'Tumor-Nodes-Metastases Classification.

Table 1: Clinicopathologic features of ES samples

A

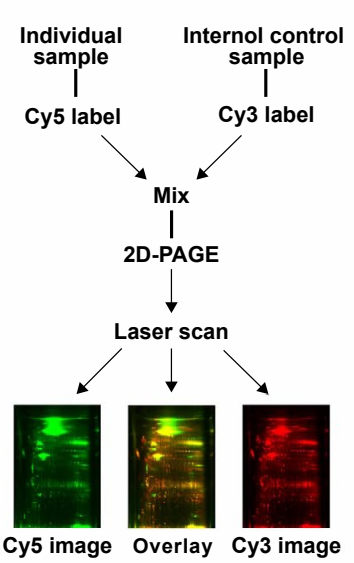

C

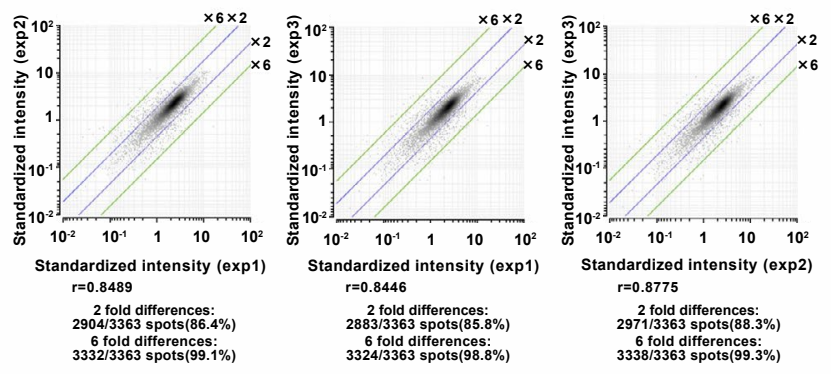

Figure 1: An overview of the experimental procedure for 2D-DIGE experiments with an internal control sample. A. The internal control and the individual sample are labeled with Cy 3 and Cy5, respectively, mixed together, and separated by 2D-PAGE. After electrophoresis, the gel is laser-scanned, and the Cy3 and Cy5 images are obtained. The Cy5 image data are normalized with the Cy3 image data to compensate for any gel-to-gel variation. B. A typical gel image of the Cy3-labeled internal control sample. The spot numbers correspond to those in Figure 2 and Table 2. C. System reproducibility was evaluated by running the identical sample three times, and reproducibility was evaluated using a scattergram.

supernatant was recovered as the protein sample.

Protein expression profiling was performed by 2D-DIGE as described previously [14]. Figure 1A gives an overview of the 2D-DIGE protocol. In brief, the internal control sample was prepared by mixing together a small portion of the samples from all individuals. Fivemicrogram portions of the internal control sample and each individual sample were labeled with Cy3 and Cy5, respectively (CyDye DIGE Fluor saturation dye, GE Healthcare Biosciences, Uppsala, Sweden) $[15,16]$. The differently labeled protein samples were mixed, and then separated by two-dimensional gel electrophoresis. The first-dimension separation was achieved using Immobiline $\mathrm{pH}$ gradient DryStrip gels (24 cm long, pI range 3-10, GE Healthcare Biosciences) [17]. The second-dimension separation was achieved by SDS-PAGE using our original large-format electrophoresis apparatus $(33-\mathrm{cm}$ separation distance, Bio-craft, Tokyo, Japan) [14]. The gels were scanned using a laser scanner (Typhoon Trio, GE Healthcare Biosciences) at appropriate wavelengths for $\mathrm{Cy} 3$ and $\mathrm{Cy} 5$. For all protein spots, the Cy5 intensity was normalized against Cy3 intensity in the same gel using the ProgenesisSameSpots software package version 3 (Nonlinear Dynamics, Newcastle-upon-Tyne, UK), in order to compensate for gelto-gel variations. All samples were examined in triplicate gels, and the mean normalized intensity value was used for comparative study.

\section{Statistical analysis}

Statistical comparisons were performed using the Expressionist software package (GeneData, Basel, Switzerland).

\section{Protein identification by mass spectrometry}

Mass spectrometric protein identification was performed as described previously [14]. In brief, $100 \mu \mathrm{g}$ of the protein sample was labeled with Cy5, and separated by 2D-PAGE as described above. Protein spots were recovered from the gels using our original automated spot recovery device, and digested to tryptic peptides by ingel digestion. The peptides were subjected to liquid chromatography coupled with nanoelectrospray tandem mass spectrometry (Finnigan LTQ Orbitrap mass spectrometer and LTQ linear ion trap mass spectrometer, Thermo Electron Co., San Jose, CA). The Mascot software package (version 2.2; Matrix Science, London, UK) and SWISS-PROT database (Homo sapiens, 471472 sequences in the Sprot-57.5.fasta file) were used for protein identification. Proteins with a Mascot score of 34 or more were considered to be positively identified.

\section{Western blotting}

Proteins were separated by SDS-PAGE and transferred to nitrocellulose membranes. Each membrane was incubated with mouse monoclonal antibody against CAPZB (1:500 dilution, Santa Cruz Biotechnology Inc, Santa Cruz, CA), and reacted with a horseradish 
peroxidase-conjugated secondary antibody (1:1000 dilution, GE Healthcare Biosciences). The immunocomplex was detected using an enhanced chemiluminescence system (ECL Prime, GE Healthcare Biosciences), and the signal was monitored with a LAS-3000 laser scanner (FujiFilm, Tokyo, Japan). The membranes were then stained with $0.2 \%$ Ponceau S and $1 \%$ acetic acid (Sigma Aldrich, St. Louis, MO) $[18,19]$, and the intensity of the protein bands was measured using the ImageQuant software package (GE Healthcare Biosciences). The intensity of individual protein bands was normalized against that of the entire lane.

\section{Immunohistochemistry}

Immunohistochemical examination was performed using formalinfixed, paraffin-embedded tissues. In brief, paraffin sections of $4-\mu \mathrm{m}$ thickness was cut from the representative block for each tumor and routinely deparaffinized. For INI1 staining, the sections were exposed to $3 \%$ hydrogen peroxide for $15 \mathrm{~min}$ to block endogenous peroxidase activity. The preparations were autoclaved in Targeted Retrieval Solution (Dako, Glostrup, Denmark) for antigen retrieval. The primary antibody used was INI1 (25/BAF47, 1:100; BD Biosciences, Franklin Lakes, NJ). The slides were incubated for $1 \mathrm{~h}$ at room temperature with the primary antibody and subsequently detected by the EnVision detection system with Linker (Dako). Diaminobenzidine was used as the chromogen, and hematoxylin as the counter stain. Complete loss of nuclear reactivity in the background of the non-neoplastic internal positive controls was regarded as deficient. For CAPZB staining, the slides were autoclaved in Tris-EDTA buffer $\left(\mathrm{pH} \mathrm{9.0)}\right.$ at $121^{\circ} \mathrm{C}$ for $30 \mathrm{~min}$ and incubated with a commercial monoclonal antibody against CAPZB (1:500 dilution; Santa Cruz Biotechnology Inc.). Immunostaining was carried out by the streptavidin-biotin peroxidase method using a Strept ABC Complex/horseradish peroxidase kit (DAKO, Glostrup, Denmark).

\section{Results and Discussion}

In order to develop clinical applications that can improve the outcome of patients with ES, it has been necessary to clarify the molecular basis of ES malignancy. The recent advent of global protein expression technologies has enabled comprehensive analysis of molecular aberrations in tumor cells, and a tremendous amount of data that may lead to clinical applications has been generated. However, the proteomic approaches have not been applied to ES, probably because of its relative rarity and the fact that clinical materials for basic research are in short supply.

In this study, we conducted a proteomic comparison between tumor and non-tumor tissues in ES. This is the first report of a proteomics approach to ES. Identification of proteins showing unique expression in tumor tissues is the first step toward clarifying the molecular basis of tumor biology. The differences between tumor and non-tumor tissues may include alterations that have occurred during carcinogenesis, or during cancer progression, and reflect the various features of malignancy including invasion, metastasis and resistance to therapy. Such a simple comparison of tumor tissues with normal ones may not in itself yield significant results, because the surrounding non-tumor tissues are not normal counterparts of tumor tissues in ES. However, investigation of the proteins identified may further our understanding of the molecular backgrounds of ES.

Here we employed 2D-DIGE to investigate the proteomic background of ES. 2D-DIGE is an advanced version of 2D-PAGE, which has been widely used to examine protein expression profiles since 1975. Although 2D-PAGE has been used for protein research for an exceptionally long period, it has a number of inherent drawbacks, one of which is gel-to-gel variations. We attempted to resolve this issue using a common internal control sample in 2D-DIGE (Figure 1A), and thus successfully compensated for any gel-to-gel variations (Figure 1C). Generally, the separation performance of gel-based proteomics parallels the separation distance achieved by electrophoresis. For longer separation distance, we developed our original large-format electrophoresis apparatus, and we successfully observed 3363 protein spots using it (Figure 1B). In 2D-DIGE, proteins are detected by laser scanning of the gels sandwiched between low-fluorescence glass plates. Therefore, a gel as large as the laser scanning area can be used without any risk of breaking the fragile polyacrylamide gel. The higher separation performance may also contribute to the high reproducibility of protein expression profiling (Figure 1C). When we ran an identical sample three times independently, the intensity of at least $85.8 \%$ of 3363 protein spots observed was scattered within a difference of twofold, and showed a relative correlation of at least 0.84 . As the intensity of at least $98.8 \%$ of the 3363 protein spots was scattered within a sixfold difference range, we further examined spots that showed more than a six-fold difference in intensity between tumor and non-tumor tissues. The intensities of all 3363 protein spots are summarized in Supplementary Table 1.

We identified 91 protein spots whose intensity differed significantly ( $p<0.01,>6$-fold ratio of means) between tumor and non-tumor tissues. These 91 spots are localized on the 2D image shown in Figure 1B. The normalized and averaged intensity of the 91 spots is shown in the form of a heat map in Figure 2, which was created using the data in Supplementary Table 1. Mass spectrometric protein identification revealed that the 91 protein spots corresponded to 69 distinct gene products (Figure 2 and Table 2). Generally, gene products are modified after transcription and translation, and single genes can generate multiple protein forms. Thus, the molecular events that had given rise to the multiple protein forms of these 69 genes, and how they differed between tumor and non-tumor tissues, were clearly of interest. Supplementary Table 2 summarizes the supporting data used for identification of these proteins. Generally, proteome data are biased by proteomics technologies, and we observe what we can observe in given technical conditions. As only proteins with differential expression were subjected to mass spectrometric protein identification, we cannot evaluate the limitation of 2D-DIGE. However, 2D-DIGE in this study clearly has limitation. For example, only the proteins with pI ranging between 4 and 7 were included in this study, and the proteins with $\mathrm{pI}$ higher than 7 were not considered. Moreover, the proteins with low expression level such as transcription factors may not be included either. Indeed, we didn't identify the products of SMARCB1/INI1, whose unique expression was reported in ES. Generally, proteomics modalities also have their own technical limitations, and there is no almighty proteomics modality. Therefore, the combined use of multiple proteomics modalities is required for comprehensive protein expression study. We demonstrated the presence of proteins with differential expression between tumor and non-tumor tissues using 2D-DIGE, and we hope that our proteomic study facilitates further investigation of ES at the protein level.

Among them, we examined the differential expression of CAPZB [20], which was up-regulated in ES tumor tissues (Figure 2 and Table 2). CAPZB is a member of the F-actin capping protein family, which bind the barbed ends of actin and regulate cell morphology and cytoskeletal organization [21]. Although CAPZB has been reported in human salivary gland cancer [22], its roles in other types of cancer have not 
Citation: Mukaihara K, Kubota D, Yoshida A, Asano N, Suehara Y, et al. (2014) Proteomic Profile of Epithelioid Sarcoma. J Proteomics Bioinform 7: 158-165. doi:10.4172/0974-276X.1000316

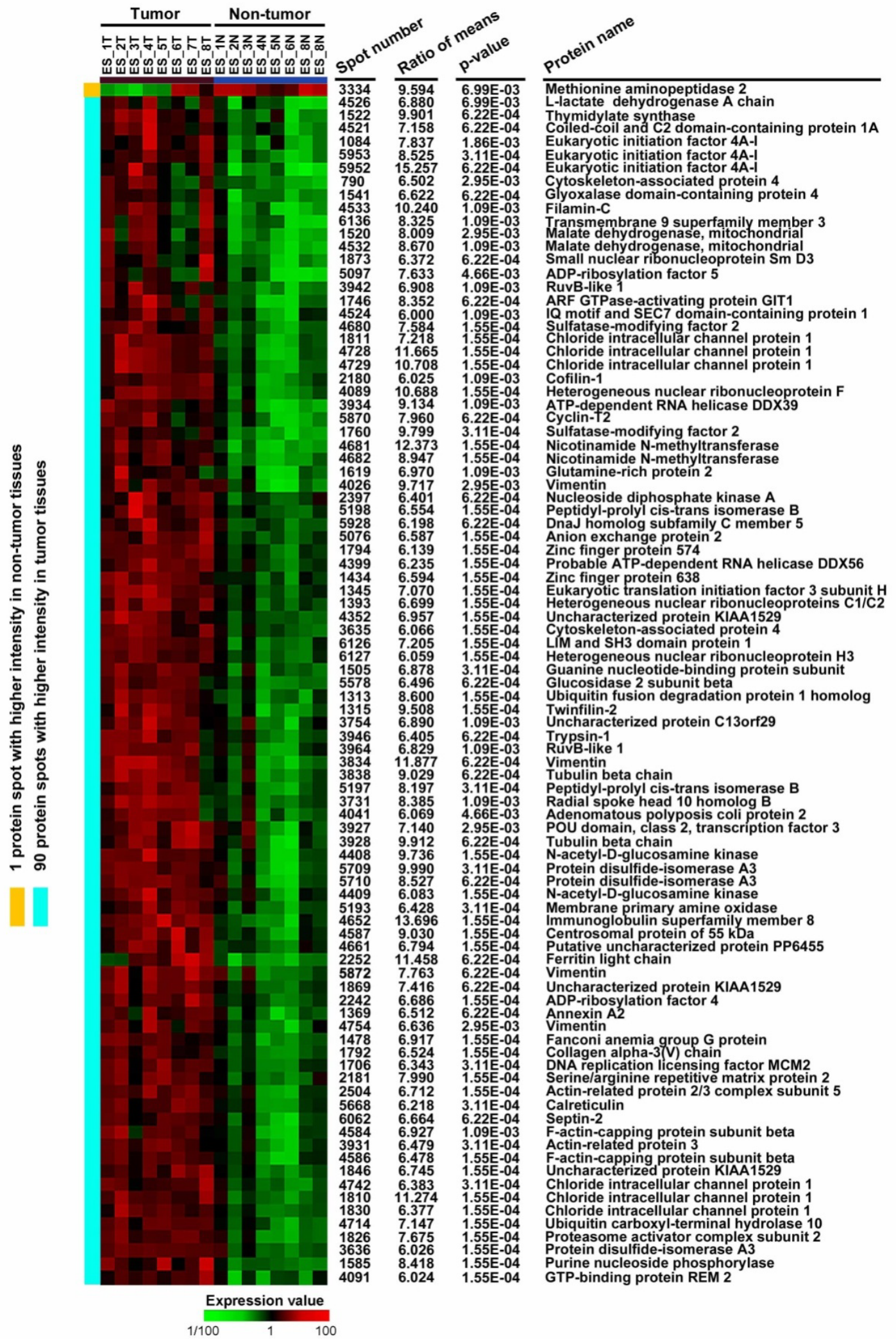

Figure 2: Results of comparative 2D-DIGE and protein identification by mass spectrometry. The results of the protein expression study are summarized in the form of a heat map. The results of protein identification are shown on the left side of the heat map. The protein spot numbers correspond to those in Figure $1 \mathrm{~B}$ and Table 2. 
Citation: Mukaihara K, Kubota D, Yoshida A, Asano N, Suehara Y, et al. (2014) Proteomic Profile of Epithelioid Sarcoma. J Proteomics Bioinform 7: 158-165. doi:10.4172/0974-276X.1000316

\begin{tabular}{|c|c|c|c|c|c|c|c|c|c|c|}
\hline Spot no. ${ }^{a}$ & $\begin{array}{c}\text { Accession } \\
\text { no. }^{\mathrm{b}}\end{array}$ & Symbol & Identified protein & $P$ value & $\begin{array}{c}\text { Fold } \\
\text { difference }\end{array}$ & $\begin{array}{c}p^{\mathbf{c}} \\
\text { (obs) }\end{array}$ & $\begin{array}{c}\text { MW c } \\
\text { (obs)(Da) }\end{array}$ & $\begin{array}{l}\text { Protein } \\
\text { score }^{d}\end{array}$ & $\begin{array}{c}\text { Peptide } \\
\text { matches }\end{array}$ & $\begin{array}{c}\text { Peptide } \\
\text { sequence } \\
\text { coverage (\%) }\end{array}$ \\
\hline 790 & Q07065 & CKAP4 & Cytoskeleton-associated protein 4 & 2.95E-03 & 6.502 & 5.63 & 66097 & 1007 & 21 & 38 \\
\hline 1084 & B4E102 & IF4A1 & Eukaryotic initiation factor $4 \mathrm{~A}-\mathrm{I}$ & 1.86E-03 & 7.837 & 5.32 & 46353 & 68 & 1 & 2.5 \\
\hline 1313 & Q92890 & UFD1 & Ubiquitin fusion degradation protein 1 homolog & 1.55E-04 & 8.600 & 6.27 & 34763 & 59 & 1 & 4.9 \\
\hline 1315 & Q6IBS0 & TWF2 & Twinfilin-2 & 1.55E-04 & 9.508 & 6.37 & 39751 & 593 & 13 & 36.1 \\
\hline 1345 & 015372 & EIF3H & Eukaryotic translation initiation factor 3 subunit $\mathrm{H}$ & $1.55 \mathrm{E}-04$ & 7.070 & 6.09 & 40076 & 102 & 2 & 5.4 \\
\hline 1369 & P07355 & ANXA2 & Annexin A2 & $6.22 \mathrm{E}-04$ & 6.512 & 7.57 & 38808 & 316 & 6 & 18.3 \\
\hline 1393 & P07910 & HNRPC & Heterogeneous nuclear ribonucleoproteins $\mathrm{C} 1 / \mathrm{C} 2$ & 1.55E-04 & 6.699 & 4.95 & 33707 & 192 & 5 & 15.4 \\
\hline 1434 & Q14966 & ZN638 & Zinc finger protein 638 & 1.55E-04 & 6.594 & 6.02 & 221914 & 48 & 1 & 1.2 \\
\hline 1478 & 015287 & FANCG & Fanconi anemia group $\mathrm{G}$ protein & 1.55E-04 & 6.917 & 5.32 & 69423 & 45 & 1 & 2.7 \\
\hline 1505 & G3V2C9 & GBLP & Guanine nucleotide-binding protein subunit beta-2-like 1 & 3.11E-04 & 6.878 & 7.6 & 35511 & 508 & 8 & 30 \\
\hline 1520 & P40926 & MDHM & Malate dehydrogenase, mitochondrial & 2.95E-03 & 8.009 & 8.92 & 35937 & 48 & 1 & 3.3 \\
\hline 1522 & P04818 & TYSY & Thymidylate synthase & $6.22 \mathrm{E}-04$ & 9.901 & 6.51 & 35978 & 440 & 9 & 28.1 \\
\hline 1541 & Q9HC38 & GLOD4 & Glyoxalase domain-containing protein 4 & $6.22 \mathrm{E}-04$ & 6.622 & 5.4 & 35170 & 51 & 1 & 4.2 \\
\hline 1585 & P00491 & PNPH & Purine nucleoside phosphorylase & 1.55E-04 & 8.418 & 6.45 & 32325 & 784 & 20 & 55.4 \\
\hline 1619 & Q9H0J4 & QRIC2 & Glutamine-rich protein 2 & 1.09E-03 & 6.970 & 6.25 & 181228 & 40 & 1 & 0.5 \\
\hline 1706 & P49736 & MCM2 & DNA replication licensing factor MCM2 & 3.11E-04 & 6.343 & 5.34 & 102516 & 42 & 1 & 2.7 \\
\hline 1746 & Q9Y2X7 & GIT1 & ARF GTPase-activating protein GIT1 & $6.22 \mathrm{E}-04$ & 8.352 & 6.33 & 85030 & 42 & 1 & 2.1 \\
\hline 1760 & Q8NBJ7 & SUMF2 & Sulfatase-modifying factor 2 & 3.11E-04 & 9.799 & 7.79 & 33950 & 83 & 2 & 8.6 \\
\hline 1792 & P25940 & CO5A3 & Collagen alpha-3(V) chain & 1.55E-04 & 6.524 & 6.37 & 172631 & 40 & 1 & 0.9 \\
\hline 1794 & Q6ZN55 & ZN574 & Zinc finger protein 574 & 1.55E-04 & 6.139 & 8.44 & 101175 & 35 & 1 & 2.1 \\
\hline 1810 & O00299 & CLIC1 & Chloride intracellular channel protein 1 & 1.55E-04 & 11.274 & 5.09 & 27248 & 296 & 4 & 20.7 \\
\hline 1811 & Q9HCl6 & CLIC1 & Chloride intracellular channel protein 1 & $1.55 \mathrm{E}-04$ & 7.218 & 5.09 & 27248 & 276 & 4 & 20.7 \\
\hline 1826 & Q9UL46 & PSME2 & Proteasome activator complex subunit 2 & 1.55E-04 & 7.675 & 5.44 & 27515 & 280 & 5 & 23 \\
\hline 1830 & O00299 & CLIC1 & Chloride intracellular channel protein 1 & 1.55E-04 & 6.377 & 5.09 & 27248 & 227 & 3 & 17.4 \\
\hline 1846 & Q9HCl6 & K1529 & Uncharacterized protein KIAA1529 & 1.55E-04 & 6.745 & 5.74 & 192404 & 48 & 2 & 1.2 \\
\hline 1869 & Q9HCl7 & K1529 & Uncharacterized protein KIAA1529 & $6.22 \mathrm{E}-04$ & 7.416 & 5.74 & 192404 & 46 & 4 & 1.2 \\
\hline 1873 & P62318 & SMD3 & Small nuclear ribonucleoprotein Sm D3 & $6.22 \mathrm{E}-04$ & 6.372 & 10.33 & 14021 & 35 & 1 & 8.7 \\
\hline 2180 & P23528 & COF1 & Cofilin-1 & $1.09 \mathrm{E}-03$ & 6.025 & 8.22 & 18719 & 293 & 4 & 37.3 \\
\hline 2181 & Q9UQ35 & SRRM2 & Serine/arginine repetitive matrix protein 2 & 1.55E-04 & 7.990 & 12.05 & 300179 & 36 & 1 & 1.1 \\
\hline 2242 & P18085 & ARF4 & ADP-ribosylation factor 4 & 1.55E-04 & 6.686 & 6.59 & 20612 & 168 & 3 & 15.6 \\
\hline 2252 & P02792 & FRIL & Ferritin light chain & $6.22 \mathrm{E}-04$ & 11.458 & 5.51 & 20064 & 125 & 2 & 17.1 \\
\hline 2397 & C9K028 & NDKA & Nucleoside diphosphate kinase A & $6.22 \mathrm{E}-04$ & 6.401 & 5.83 & 17309 & 447 & 13 & 64.5 \\
\hline 2504 & 015511 & ARPC5 & Actin-related protein $2 / 3$ complex subunit 5 & 1.55E-04 & 6.712 & 5.47 & 16367 & 293 & 7 & 29.1 \\
\hline 3334 & P50579 & AMPM2 & Methionine aminopeptidase 2 & 6.99E-03 & 9.594 & 5.57 & 53713 & 36 & 1 & 3.6 \\
\hline 3635 & Q07065 & CKAP4 & Cytoskeleton-associated protein 4 & 1.55E-04 & 6.066 & 5.63 & 66097 & 1209 & 18 & 38.7 \\
\hline 3636 & P30101 & PDIA3 & Protein disulfide-isomerase A3 & 1.55E-04 & 6.026 & 5.98 & 57146 & 1312 & 25 & 46.1 \\
\hline 3731 & P0C881 & R10B1 & Radial spoke head 10 homolog B & 1.09E-03 & 8.385 & 7.16 & 101255 & 35 & 1 & 2 \\
\hline 3754 & Q8IVM7 & CM029 & Uncharacterized protein C13orf29 & 1.09E-03 & 6.890 & 9.29 & 18425 & 39 & 1 & 11 \\
\hline 3834 & P08670 & VIME & Vimentin & $6.22 \mathrm{E}-04$ & 11.877 & 5.06 & 53676 & 1794 & 41 & 60.3 \\
\hline 3838 & E9PBJ4 & TBB5 & Tubulin beta chain & $6.22 \mathrm{E}-04$ & 9.029 & 4.78 & 50095 & 301 & 8 & 13.7 \\
\hline 3927 & Q9VKI9 & PO2F3 & POU domain, class 2 , transcription factor 3 & 2.95E-03 & 7.140 & 8.81 & 47764 & 36 & 1 & 3.9 \\
\hline 3928 & E9PBJ4 & TBB5 & Tubulin beta chain & $6.22 \mathrm{E}-04$ & 9.912 & 4.78 & 50095 & 310 & 7 & 15.3 \\
\hline 3931 & P61158 & ARP3 & Actin-related protein 3 & $3.11 \mathrm{E}-04$ & 6.479 & 5.61 & 47797 & 618 & 12 & 25.6 \\
\hline 3934 & 000148 & DDX39 & ATP-dependent RNA helicase DDX39 & 1.09E-03 & 9.134 & 5.46 & 49611 & 533 & 10 & 25.1 \\
\hline 3942 & Q9Y265 & RUVB1 & RuvB-like 1 & 1.09E-03 & 6.908 & 6.02 & 50538 & 175 & 4 & 8.6 \\
\hline 3946 & E7EQ64 & TRY1 & Trypsin-1 & $6.22 \mathrm{E}-04$ & 6.405 & 6.08 & 27111 & 46 & 1 & 4 \\
\hline 3964 & Q9Y265 & RUVB1 & RuvB-like 1 & 1.09E-03 & 6.829 & 6.02 & 50538 & 984 & 17 & 37.3 \\
\hline 4026 & P08670 & VIME & Vimentin & 2.95E-03 & 9.717 & 5.06 & 53676 & 167 & 3 & 7.9 \\
\hline 4041 & O95996 & APC2 & Adenomatous polyposis coli protein 2 & 4.66E-03 & 6.069 & 9.08 & 245966 & 36 & 1 & 0.6 \\
\hline 4089 & P52597 & HNRPF & Heterogeneous nuclear ribonucleoprotein F & 1.55E-04 & 10.688 & 5.38 & 45985 & 146 & 2 & 8 \\
\hline 4091 & Q8IYK8 & REM2 & GTP-binding protein REM 2 & 1.55E-04 & 6.024 & 9.19 & 36170 & 38 & 1 & 8.5 \\
\hline 4352 & B1AK85 & K1529 & Uncharacterized protein KIAA1529 & 1.55E-04 & 6.957 & 5.74 & 192404 & 44 & 3 & 1.2 \\
\hline 4399 & Q9NY93 & DDX56 & Probable ATP-dependent RNA helicase DDX56 & 1.55E-04 & 6.235 & 9.34 & 62007 & 37 & 1 & 3.8 \\
\hline 4408 & Q9UJ70 & NAGK & $\mathrm{N}$-acetyl-D-glucosamine kinase & $1.55 \mathrm{E}-04$ & 9.736 & 5.81 & 37694 & 216 & 4 & 12.8 \\
\hline 4409 & Q9UJ70 & NAGK & $\mathrm{N}$-acetyl-D-glucosamine kinase & $1.55 \mathrm{E}-04$ & 6.083 & 5.81 & 37694 & 513 & 8 & 28.5 \\
\hline 4521 & Q6P1NO & C2D1A & Coiled-coil and $\mathrm{C} 2$ domain-containing protein $1 \mathrm{~A}$ & $6.22 \mathrm{E}-04$ & 7.158 & 8.22 & 104397 & 51 & 1 & 1.6 \\
\hline 4524 & Q6DN90 & IQEC1 & IQ motif and SEC7 domain-containing protein 1 & 1.09E-03 & 6.000 & 6.49 & 109103 & 34 & 1 & 1 \\
\hline 4526 & P00338 & LDHA & L-lactate dehydrogenase A chain & $6.99 \mathrm{E}-03$ & 6.880 & 8.44 & 36950 & 247 & 4 & 12 \\
\hline
\end{tabular}




\begin{tabular}{|c|c|c|c|c|c|c|c|c|c|c|}
\hline 4532 & A6NHQ2 & FBLL1 & rRNA/tRNA 2 -O-methyltransferase fibrillarin-like protein 1 & 1.09E-03 & 8.670 & 10.33 & 34711 & 41 & 1 & 3.6 \\
\hline 4533 & Q14315 & FLNC & Filamin-C & 1.09E-03 & 10.240 & 5.68 & 293344 & 39 & 1 & 0.4 \\
\hline 4584 & P47756 & CAPZB & F-actin-capping protein subunit beta & 1.09E-03 & 6.927 & 5.36 & 31616 & 518 & 11 & 28.2 \\
\hline 4586 & P47756 & CAPZB & F-actin-capping protein subunit beta & $1.55 \mathrm{E}-04$ & 6.478 & 5.36 & 31616 & 431 & 9 & 21.7 \\
\hline 4587 & Q53EZ4 & CEP55 & Centrosomal protein of $55 \mathrm{kDa}$ & 1.55E-04 & 9.030 & 6.52 & 54433 & 38 & 1 & 2.6 \\
\hline 4652 & Q969P0 & IGSF8 & Immunoglobulin superfamily member 8 & 1.55E-04 & 13.696 & 8.23 & 65621 & 35 & 1 & 1.6 \\
\hline 4661 & Q8WZ26 & YS006 & Putative uncharacterized protein PP6455 & $1.55 \mathrm{E}-04$ & 6.794 & 8.26 & 15165 & 35 & 1 & 6.7 \\
\hline 4680 & Q8NBJ7 & SUMF2 & Sulfatase-modifying factor 2 & 1.55E-04 & 7.584 & 7.79 & 33950 & 119 & 2 & 8.6 \\
\hline 4681 & P40261 & NNMT & Nicotinamide $\mathrm{N}$-methyltransferase & 1.55E-04 & 12.373 & 5.56 & 30011 & 239 & 4 & 17.4 \\
\hline 4682 & P40261 & NNMT & Nicotinamide N-methyltransferase & 1.55E-04 & 8.947 & 5.56 & 30011 & 104 & 2 & 7.6 \\
\hline 4714 & Q14694 & UBP10 & Ubiquitin carboxyl-terminal hydrolase 10 & 1.55E-04 & 7.147 & 5.19 & 87707 & 35 & 1 & 1.9 \\
\hline 4728 & O00299 & CLIC1 & Chloride intracellular channel protein 1 & 1.55E-04 & 11.665 & 5.09 & 27248 & 320 & 5 & 24.1 \\
\hline 4729 & O00299 & CLIC1 & Chloride intracellular channel protein 1 & 1.55E-04 & 10.708 & 5.09 & 27248 & 176 & 3 & 17.4 \\
\hline 4742 & O00299 & CLIC1 & Chloride intracellular channel protein 1 & 3.11E-04 & 6.383 & 5.09 & 27248 & 60 & 1 & 5 \\
\hline 4754 & P08670 & VIME & Vimentin & 2.95E-03 & 6.636 & 5.06 & 53676 & 212 & 4 & 10.5 \\
\hline 5076 & C9J035 & B3A2 & Anion exchange protein 2 & 1.55E-04 & 6.587 & 5.9 & 137493 & 41 & 1 & 1 \\
\hline 5097 & P84085 & ARF5 & ADP-ribosylation factor 5 & 4.66E-03 & 7.633 & 6.3 & 20631 & 278 & 5 & 34.4 \\
\hline 5193 & Q16853 & $\mathrm{AOC} 3$ & Membrane primary amine oxidase & 3.11E-04 & 6.428 & 6.05 & 85138 & 37 & 1 & 2.5 \\
\hline 5197 & P23284 & PPIB & Peptidyl-prolyl cis-trans isomerase B & 3.11E-04 & 8.197 & 9.42 & 23785 & 427 & 11 & 34.7 \\
\hline 5198 & P23284 & PPIB & Peptidyl-prolyl cis-trans isomerase B & 1.55E-04 & 6.554 & 9.42 & 23785 & 202 & 5 & 23.6 \\
\hline 5578 & P14314 & GLU2B & Glucosidase 2 subunit beta & $6.22 \mathrm{E}-04$ & 6.496 & 4.33 & 60357 & 205 & 3 & 8.1 \\
\hline 5668 & P27797 & CALR & Calreticulin & 3.11E-04 & 6.218 & 4.29 & 48283 & 213 & 5 & 8.6 \\
\hline 5709 & P30101 & PDIA3 & Protein disulfide-isomerase A3 & 3.11E-04 & 9.990 & 5.98 & 57146 & 565 & 12 & 22.8 \\
\hline 5710 & P30101 & PDIA3 & Protein disulfide-isomerase $\mathrm{A} 3$ & $6.22 \mathrm{E}-04$ & 8.527 & 5.98 & 57146 & 696 & 12 & 26.1 \\
\hline 5870 & 060583 & CCNT2 & Cyclin-T2 & 6.22E-04 & 7.960 & 9.04 & 81492 & 39 & 1 & 1.6 \\
\hline 5872 & P08670 & VIME & Vimentin & $6.22 \mathrm{E}-04$ & 7.763 & 5.06 & 53676 & 952 & 22 & 37.1 \\
\hline 5928 & Q9H3Z4 & DNJC5 & DnaJ homolog subfamily $\mathrm{C}$ member 5 & $6.22 \mathrm{E}-04$ & 6.198 & 4.93 & 22933 & 43 & 1 & 10.1 \\
\hline 5952 & Q07065 & IF4A1 & Eukaryotic initiation factor $4 \mathrm{~A}-\mathrm{I}$ & $6.22 \mathrm{E}-04$ & 15.257 & & 46353 & & 1 & 2.5 \\
\hline 5953 & Q07065 & IF4A1 & Eukaryotic initiation factor $4 \mathrm{~A}-\mathrm{I}$ & 3.11E-04 & 8.525 & & 46353 & & 10 & 23.4 \\
\hline 6062 & Q15019 & SEPT & Septin-2 & $6.22 \mathrm{E}-04$ & 6.664 & & 41689 & & 3 & 8.6 \\
\hline 6126 & Q14847 & LASP1 & LIM and SH3 domain protein 1 & 1.55E-04 & 7.205 & & 30097 & & 3 & 15.3 \\
\hline 6127 & B4DHY1 & HNRH3 & Heterogeneous nuclear ribonucleoprotein $\mathrm{H} 3$ & 1.55E-04 & 6.059 & & 36960 & & 1 & 3.5 \\
\hline 6136 & Q5TB53 & TM9S3 & Transmembrane 9 superfamily member 3 & 1.09E-03 & 8.325 & & 68584 & & 1 & 2 \\
\hline \multicolumn{11}{|c|}{$\begin{array}{l}\text { aSpot numbers refer to those in Figure 1B. } \\
\text { bAccession numbers of proteins were derived from Swiss-Plot and NBCI nonredundant data bases. } \\
\text { cObserved isoelectric point and molecular weight calculated according to location on the } 2 \mathrm{D} \text { gel. } \\
\text { dMascot score for the identified proteins based on the peptide ions score }(p<0.05) \text { (http://www.mat }\end{array}$} \\
\hline
\end{tabular}

Table 2: A list of identified proteins with differential expression between tumor and non-tumor tissues in ES patients.

been investigated. The family protein of CAPZB was implemented in the other types of cancers. For instance, using a proteomics approach, we previously found that macrophage-capping protein (CapG), an actin-capping protein that blocks the barbed ends of F-actin filaments, was associated with resistance of cholangiocellular carcinoma (CCC) to gemcitabine therapy, and using immunohistochemistry we also found that CapG in tumor cells had prognostic utility [23]. Using a proteomics approach, we also found that CapG in tumor tissues was significantly associated with malignant features of gastric cancer [24]. In liver cancer, we reported that CapG was highly expressed in primary tumor tissues with intravascular metastasis [25], and the expression of CapG was confirmed in tumor cells by immnuhositochemistry and the functional significances of CapG in liver cancer cells were confirmed by in vitro experiments. In breast cancer, higher expression of CapG was observed at the tumor margin, suggesting that that CapG may be involved in tumor cell dissemination and metastasis [26]. These observations suggest that CapG may have diagnostic utility. Recently, van Impe et al. [27] developed a novel nanobody, which is a singledomain antibody, against CapG, and delivered it to breast cancer cells by lentiviral transduction. This resulted in attenuation of cell migration and lung metastasis, and suggested that CapG may have utility as a therapeutic target. As CAPZB has a function similar to that of CapG in actin organization, we further investigated the expression of CAPZB in tumor tissues of ES.

We confirmed overexpression of CAPZB in ES using Western blotting (Figure 3A). In all eight ES cases, we found that CAPZB was highly expressed in tumor tissues relative to adjacent non-tumor tissues $(p<0.01$, Figure $3 B$ ). These observations were consistent with those of 2D-DIGE, and mass spectrometry supported the correct identification of the protein.

We tried to localize the expression of CAPZB in specific cell types by immunohistochemistry. The immunohistochemical examination is critical in the proteomic study of ES when the tissues are homogenized for protein extraction. The tumor tissues of ES are highly complex, and the proteomic data of the homogenized tissue samples should consist of the mixed proteome data of different cell types. The laser microdissection was often employed to approach the tissue complexity. However, as the conventional laser microdissection for 2D-DIGE does not recover individual single cells [14], it cannot solve the problem of high tissue complexity of ES. To determine the expression of given proteins in tumor cells, immunohistochemistry is mandatory. Without localization data, the further in vitro functional studies cannot be significant. We stained the sectioned tissues with the antibody 


\section{A}

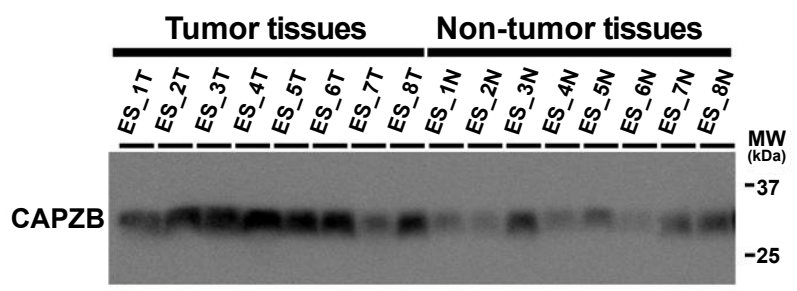

B

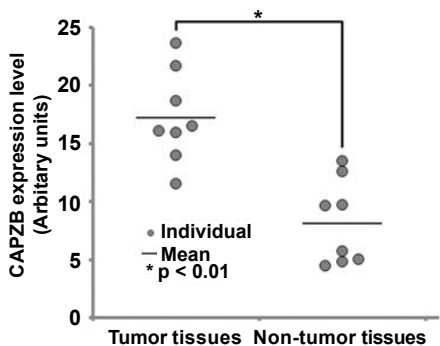

Figure 3: Validation study of the expression of CAPZB in tumor and nontumor tissues. Western blotting shows that CAPZB was highly expressed in tumor tissues, relative to adjacent non-tumor tissues (A). Quantified data from Western blotting show that CAPZB expression was significantly higher in tumor tissues than in non-tumor tissues $(p<0.01)(B)$.

against CAPZB, which was used for Western blotting. We found that the immunohistochemical staining patterns of CAPZB was not conclusive; the immnuhistochemical signals of CAPZB seemed to be non specific and the cellular localization of CAPZB were not consistent among the tissue sections. It may be reasoned by the characters of antibody used in this study; the indication of CAPZB antibody for immunohistochemistry was not guaranteed by antibody supplier. Presently, we could not concluded the cell types where CAPZB localized in tumor tissues of ES. It is worth screening the antibodies which can clearly localize CAPZB in tumor tissues.

Our present study has demonstrated that a proteomics approach can generate intriguing results using tissue samples. At the same time, our study clearly indicated the difficult part of tissue proteomics. Tumor tissues generally contain multiple types of cells, and localization of proteins identified by tissue proteomics should be determined prior to further examinations. However, laser microdissection may not always be a solution for tissue complexity, and immnuhistochemical examination to localize the identified proteins does not always work as expected. This inherent drawback of tissue proteomics should be considered when we interpret the proteome data of ES in this study.

\section{Acknowledgements}

This work was supported by the National Cancer Center Research Core Facility and the National Cancer Center Research and Development Fund (23-A-7, 23-A-10, and 26-A-9). We appreciate an excellent technical support by Yukiko Nakamura (National Cancer Center Research Institute).

\section{References}

1. Enzinger FM (1970) Epitheloid sarcoma. A sarcoma simulating a granuloma or a carcinoma. Cancer 26: 1029-1041.

2. Chase DR, Enzinger FM (1985) Epithelioid sarcoma. Diagnosis, prognostic indicators, and treatment. Am J Surg Pathol 9: 241-263.

3. Guillou L, Wadden C, Coindre JM, Krausz T, Fletcher CD (1997) "Proximal- type" epithelioid sarcoma, a distinctive aggressive neoplasm showing rhabdoid features. Clinicopathologic, immunohistochemical, and ultrastructural study of a series. Am J Surg Pathol 21: 130-146.

4. Chbani L, Guillou L, Terrier P, Decouvelaere AV, Grégoire F, et al. (2009) Epithelioid sarcoma: a clinicopathologic and immunohistochemical analysis of 106 cases from the French sarcoma group. Am J Clin Pathol 131: 222-227.

5. Fisher C (2006) Epithelioid sarcoma of Enzinger. Adv Anat Pathol 13: 114-121.

6. Evans HL, Baer SC (1993) Epithelioid sarcoma: a clinicopathologic and prognostic study of 26 cases. Semin Diagn Pathol 10: 286-291.

7. Baratti D, Pennacchioli E, Casali PG, Bertulli R, Lozza L, et al. (2007) Epithelioid sarcoma: prognostic factors and survival in a series of patients treated at a single institution. Ann Surg Oncol 14: 3542-3551.

8. Modena P, Lualdi E, Facchinetti F, Galli L, Teixeira MR, et al. (2005) SMARCB1/ INI1 tumor suppressor gene is frequently inactivated in epithelioid sarcomas. Cancer Res 65: 4012-4019.

9. Hornick JL, Dal Cin P, Fletcher CD (2009) Loss of INI1 expression is characteristic of both conventional and proximal-type epithelioid sarcoma. Am J Surg Pathol 33: 542-550.

10. Brenca M, Rossi S, Lorenzetto E, Piccinin E, Piccinin S, et al. (2013) SMARCB1/ INI1 genetic inactivation is responsible for tumorigenic properties of epithelioid sarcoma cell line VAESBJ. Mol Cancer Ther 12: 1060-1072.

11. Papp G, Krausz T, Stricker TP, Szendroi M, Sapi Z (2014) SMARCB1 expression in epithelioid sarcoma is regulated by miR-206, miR-38, and miR$671-5 p$ on Both mRNA and protein levels. Genes Chromosomes Cancer 53: 168-176.

12. Weber A, Engers R, Nockemann S, Gohr LL, Zur Hausen A, et al. (2001) Differentially expressed genes in association with in vitro invasiveness of human epithelioid sarcoma. Mol Pathol 54: 324-330.

13. Lushnikova T, Knuutila S, Miettinen M (2000) DNA copy number changes in epithelioid sarcoma and its variants: a comparative genomic hybridization study. Mod Pathol 13: 1092-1096.

14. Kondo T, Hirohashi S (2007) Application of highly sensitive fluorescent dyes (CyDye DIGE Fluor saturation dyes) to laser microdissection and twodimensional difference gel electrophoresis (2D-DIGE) for cancer proteomics. Nat Protoc 1: 2940-2956.

15. Unlü M, Morgan ME, Minden JS (1997) Difference gel electrophoresis: a single gel method for detecting changes in protein extracts. Electrophoresis 18: 20712077.

16. Shaw J, Rowlinson R, Nickson J, Stone T, Sweet A, et al. (2003) Evaluation of saturation labelling two-dimensional difference gel electrophoresis fluorescent dyes. Proteomics 3: 1181-1195.

17. Righetti PG (1990) Immobilized pH gradients: theory and methodology, Elsevier.

18. Romero-Calvo I, Ocón B, Martínez-Moya $P$, Suárez MD, Zarzuelo A et al. (2010) Reversible Ponceau staining as a loading control alternative to actin in Western blots. Anal Biochem 401: 318-320.

19. Klein D, Kern RM, Sokol RZ (1995) A method for quantification and correction of proteins after transfer to immobilization membranes. Biochem Mol Biol Int 36: 59-66.

20. Barron-Casella EA, Torres MA, Scherer SW, Heng HH, Tsui LC, et al. (1995) Sequence analysis and chromosomal localization of human Cap Z. Conserved residues within the actin-binding domain may link Cap $Z$ to gelsolin/severin and profilin protein families. J Biol Chem 270: 21472-21479.

21. Bai SW, Herrera-Abreu MT, Rohn JL, Racine V, Tajadura V, et al. (2011) Identification and characterization of a set of conserved and new regulators of cytoskeletal organization, cell morphology and migration. BMC Biol 9: 54.

22. Kamo M, Sato N (2006) Proteins profiling of human salivary intercalated duct cell line by proteomics. Japanese Journal of Tissue Culture Dental Research 15: $11-28$.

23. Morofuji N, Ojima H, Onaya H, Okusaka T, Shimada K, et al. (2012) Macrophage-capping protein as a tissue biomarker for prediction of response to gemcitabine treatment and prognosis in cholangiocarcinoma. J Proteomics 75: 1577-1589.

24. Ichikawa H, Kanda T, Kosugi S, Kawachi Y, Sasaki H, et al. (2013) Laser 
Citation: Mukaihara K, Kubota D, Yoshida A, Asano N, Suehara Y, et al. (2014) Proteomic Profile of Epithelioid Sarcoma. J Proteomics Bioinform 7: 158-165. doi:10.4172/0974-276X.1000316

microdissection and two-dimensional difference gel electrophoresis reveal the role of a novel macrophage-capping protein in lymph node metastasis in gastric cancer. J Proteome Res 12: 3780-3791.

25. Kimura K, Ojima H, Kubota D, Sakumoto M, Nakamura Y, et al. (2013) Proteomic identification of the macrophage-capping protein as a protein contributing to the malignant features of hepatocellular carcinoma. J Proteomics 78: 362-373.
26. Kang S, Kim MJ, An H, Kim BG, Choi YP, et al. (2010) Proteomic molecular portrait of interface zone in breast cancer. J Proteome Res 9: 5638-5645.

27. Van Impe K, Bethuyne J, Cool S, Impens F, Ruano-Gallego D, et al. (2013) A nanobody targeting the F-actin capping protein CapG restrains breast cancer metastasis. Breast Cancer Res 15: R116. 